UDC 519.7:338.67

DOI: $10.22363 / 2658-4670-2020-28-4-346-360$

\title{
On methods of quantitative analysis of the company's financial indicators under conditions of high risk of investments
}

\author{
Eugeny Yu. Shchetinin \\ Financial University under the Government of Russian Federation \\ 49, Leningradsky Prospect, Moscow 125993, Russian Federation
}

(received: October 30, 2020; accepted: November 12, 2020)

The paper investigates the methods of quantitative analysis of hidden statistical relationships of the financial indicators of companies under conditions of high investment risk. A new semi-parametric method for estimating tail dependence indicators using BB1 and BB7 dependence structures is proposed. For a dataset containing the cost indicators of leading Russian companies, computer experiments were carried out, as a result of which it was shown that the proposed method has a higher stability and accuracy in comparison with other considered methods. Practical application of the proposed risk management method would allow financial companies to assess investment risks adequately in the face of extreme events.

Key words and phrases: financial indicators, dependency structures of extremal type, tail ratio, copula

\section{Introduction}

The global changes currently taking place in the world financial markets caused by the global pandemic of the coronavirus COVID-19, along with a catastrophic decline in oil prices, will obviously entail the need for serious changes in the business structure of both individual companies and entire industries, regional economies and countries. In the Russian conditions of high volatility of financial markets, a successful solution to this problem is impossible without the application of an analysis of the company's resistance to the effects of the external environment, the implementation of constant monitoring of the behavior of a number of indicators of the enterprise profitability. In particular, trigger analysis [1] is one of such effective methods of analysis. The use of trigger analysis to study the sensitivity of a business structure to the impact of disturbing factors is important, since it allows identifying in advance its most weakly protected, most risky business lines, the socalled trigger points. Examples of these are individual lines of business of a company, credit and debt obligations, etc., precisely those areas of activity that potentially pose a threat of an emergency in the company. Therefore, in order to weaken

(C) Shchetinin E. Yu., 2020

This work is licensed under a Creative Commons Attribution 4.0 International License

http://creativecommons.org/licenses/by/4.0/ 
their influence on the structure as a whole, and on its individual lines, we proposed instead of the trigger point in its vicinity on the scatter diagram to form an aggregate set with the statistical properties of the meta-elliptic type dependence structure [2]. This allows weakening to certain limits the impact of the statistical dependence of the rest of the business lines on the problematic one and redistributing the aggregate damage to the rest of the business structure lines. In addition, the transition from an extreme dependence to a meta-elliptic one simplifies the calculation of structural risk indicators by the usual summation of the marginal risks for this structure. Examples of such an approach to managing extreme risks are debt-restructuring, transfer of fixed assets to subsidiaries and offshore companies, insurance, hedging (issuance of credit derivatives), limiting and securitization operations in the banking sector, etc.

This paper considers effective methods for analyzing the financial performance of companies in the face of increased volatility in stock markets associated with the global COVID-19 pandemic, as well as declining oil prices. Using the example of analyzing the value of shares of leading Russian companies, the advantages of their application are shown in comparison with the classical multivariate analysis using a Gaussian distribution.

\section{Methods for the quantitative analysis of structure indicators of statistical dependences}

Let $(X, Y)$ be a two-dimensional random variable characterized by a joint distribution function $F$ and partial distribution functions $F_{1}$ and $F_{2}$, respectively. Then the coefficient of the lower tail dependence and the coefficient of the upper tail dependence are respectively the limits

$$
\begin{aligned}
& \lambda_{L}=\lim _{v \rightarrow 0+0} P\left(X \leqslant F_{1}^{-1}(v) \mid Y \leqslant F_{2}^{-1}(v)\right), \\
& \lambda_{U}=\lim _{v \rightarrow 1-0} P\left(X>F_{1}^{-1}(v) \mid Y>F_{2}^{-1}(v)\right) .
\end{aligned}
$$

From equations (1)-(2) it obviously follows that the coefficients $\lambda_{L}$ and $\lambda_{U}$ can take the values within the limits from 0 to 1 . The case $\lambda_{L}>0$ $\left(\lambda_{U}>0\right)$ is referred to as the presence of a tail dependence or the appearance of a contagion [2] between the random variables $X$ and $Y$. The situation $\lambda_{L}=1\left(\lambda_{U}=1\right)$ corresponds to full contagion [3].

Using the concepts of copula theory [3], we can write expressions for the coefficients of the tail dependence in the following form:

$$
\begin{gathered}
\lambda_{L}=\lim _{v \rightarrow 0+0} \frac{C(v, v)}{v}, \\
\lambda_{U}=\lim _{v \rightarrow 1-0} \frac{1-2 v+C(v, v)}{1-v},
\end{gathered}
$$

where $C$ is the copula of the joint distribution of random variables. It follows from this representation that the tail dependence coefficients are a property of the dependence structure and do not depend on the partial distributions. 
In the general case of $d$-dimensional distribution of random variables $\left(X^{(1)}, \ldots, X^{(d)}\right)$, to describe the nature of the extreme dependence using the coefficients of the tail dependence, it is necessary to estimate the $\frac{d(d-1)}{2}$ pairs of values of the coefficients $\lambda_{i j}, 1 \leqslant i, j \leqslant d$. When using nonparametric methods, each pair of tail coefficients can be estimated separately, while when using para-metric and semi-parametric approaches, it is necessary to take into account the structure of the relationship between all $d$ components of the multivariate distribution.

\section{Nonparametric estimation methods}

Let $\mathbf{X}_{\mathrm{n}}, \mathbf{Y}_{\mathbf{n}}$ be samples of independent identically distributed random variables. We define the empirical copula function as

$$
C_{n}(u, v)=\frac{1}{n} \sum_{j=1}^{n} 1_{\left\{\operatorname{Rank}\left(X_{j}\right) \leqslant n \cdot u, \operatorname{Rank}\left(Y_{j}\right) \leqslant n \cdot v\right\}}
$$

Introducing the notation $U_{j}=\operatorname{Rank}\left(X_{j}\right), V_{j}=\operatorname{Rank}\left(Y_{j}\right)$, by definition of tail dependence coefficients we get

$$
\begin{gathered}
\hat{\lambda}_{L, n}(k)=\frac{n}{k} \cdot C_{n}\left(\frac{k}{n}, \frac{k}{n}\right)=\frac{1}{k} \cdot \sum_{j=1}^{n} 1_{\left\{U_{j} \leqslant k, V_{j} \leqslant k\right\}}, \\
\hat{\lambda}_{L, n}(k)=\frac{n}{k} \cdot C_{n}\left(\left(1-\frac{k}{n}, 1\right] \times\left(1-\frac{k}{n}, 1\right]\right)= \\
=\frac{1}{k} \sum_{j=1}^{n} 1_{\left\{U_{j}>n-k, V_{j}>n-k\right\}}=2-\frac{1}{k} \sum_{j=1}^{n} 1_{\left\{U_{j}>n-k \text { or } V_{j}>n-k\right\}},
\end{gathered}
$$

where $C_{n}((a, b] \times(c, d])$ is the empirical probability measure of the copula function on a rectangle $(a, b] \times(c, d], k=k(n) \rightarrow \infty, \frac{k}{n} \rightarrow 0$ at $n \rightarrow \infty$. The consistency and normality of the estimates were proved in [4]. Logarithmic parametric estimates for $\lambda_{L}$ and $\lambda_{U}$ can be obtained using equations (3), (4). Thus, the expression for the coefficient of the lower tail dependence can be represented as

$\lambda_{L}=\lim _{v \rightarrow 0+0} \frac{C(v, v)}{v}=2-\lim _{v \rightarrow 0+0} \frac{-2 v+C(v, v)}{-v}=2-\lim _{v \rightarrow 0+0} \frac{\ln (1-2 v+C(v, v))}{\ln (1-v)}$.

According to this formula, the value of $\lambda_{L}$ can be estimated as

$$
\hat{\lambda}_{L, n}^{\mathrm{LOG}}(k)=2-\frac{\ln \left(C_{n}\left(\left(\frac{k}{n}, 1\right] \times\left(\frac{k}{n}, 1\right]\right)\right)}{\ln \left(1-\frac{k}{n}\right)}=2-\frac{\ln \left(\frac{1}{n} \sum_{j=1}^{n} 1_{\left\{U_{j}>k, V_{j}>k\right\}}\right)}{\ln \left(1-\frac{k}{n}\right)},
$$


where index $k=k(n) \rightarrow \infty, \frac{k}{n} \rightarrow 0$ when $n \rightarrow \infty$. Similarly, for the coefficient of the upper tail dependence, the representation

$\lambda_{U}=\lim _{v \rightarrow 1-0} \frac{1-2 v+C(v, v)}{1-v}=2-\lim _{v \rightarrow 1-0} \frac{C(v, v)-1}{v-1}=2-\lim _{v \rightarrow 1-0} \frac{\ln (C(v, v))}{\ln (v)}$

is valid, as well as the estimate

$$
\begin{aligned}
& \hat{\lambda}_{U, n}^{\mathrm{LOG}}(k)=2-\frac{\ln \left(C_{n}\left(1-\frac{k}{n}, 1-\frac{k}{n}\right)\right)}{\ln \left(1-\frac{k}{n}\right)}= \\
& 2-\frac{\ln \left(\frac{1}{n} \sum_{j=1}^{n} 1\left\{U_{j} \leqslant n-k \operatorname{or} V_{j} \leqslant n-k\right\}\right)}{\ln \left(1-\frac{k}{n}\right)},
\end{aligned}
$$

$k=k(n) \rightarrow \infty, \frac{k}{n} \rightarrow 0$ at $n \rightarrow \infty$. Estimates (7), (8) have the property that they are sharp for all $k$ in the limiting cases of statistical independence and comonotonicity. Indeed,

$$
\begin{gathered}
\lambda_{\text {indep }, L}^{\mathrm{LOG}}=2-\frac{\ln (1-2 v+\Pi(v, v))}{\ln (1-v)}=2-\frac{\ln \left(1-2 v+v^{2}\right)}{\ln (1-v)}=0, \\
\lambda_{\text {com }, L}^{\mathrm{LOG}}=2-\frac{\ln (1-2 v+M(v, v))}{\ln (1-v)}=2-\frac{\ln (1-2 v+v)}{\ln (1-v)}=1, \\
\lambda_{\text {indep }, U}^{\mathrm{LOG}}=2-\frac{\ln (\Pi(v, v))}{\ln (v)}=2-\frac{\ln \left(v^{2}\right)}{\ln (v)}=0, \\
\lambda_{\text {com }, U}^{\mathrm{LOG}}=2-\frac{\ln (M(v, v))}{\ln (v)}=2-\frac{\ln (v)}{\ln (v)}=1,
\end{gathered}
$$

where $\Pi(u, v)=u v$ is the function of the copula of independent random variables, $M(u, v)=\min (u, v)$ is the copula of comonotonic (completely dependent) random variables. The consistency and asymptotic normality of the estimates was proved in [4]. Figure 1 plots the values of the tail ratios estimates depending on the choice of the threshold $k$ for the joint distribution of fifteen-minute logarithmic increments in the value of Rosneft and Lenta equities in the period from December 15, 2019 to September 30, 2020. In the range of stability $30 \leqslant k \leqslant 70$ of estimates, the value of the tail ratios is significantly greater than zero, which indicates a strong dependence of the investigated financial indicators in the area of extreme values. 

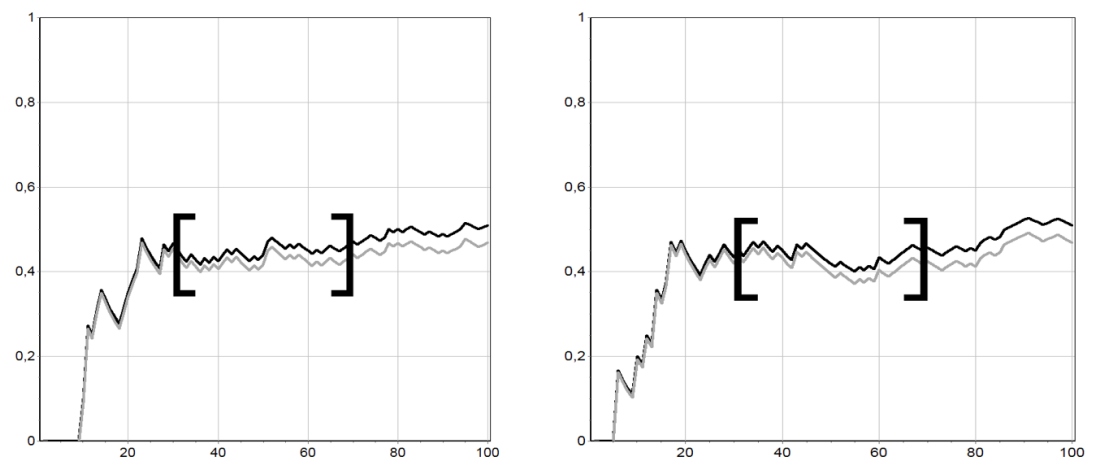

Figure 1. Estimation of indicators of the lower (left) and upper (right) tail coefficients of the joint distribution of the logarithmic increments of the value of Rosneft and Lenta shares depending on the parameter $k$.

- standard estimate (6), (7), = logarithmic estimate (8), (9)

\section{Parametric estimation methods}

The parametric approach to estimating the values of tail coefficients is based on the use of a mathematical model of the initial data structure in the form of a parametric copula $C_{\theta}$. In this case, estimates of the lower and upper coefficients of the tail dependence can be found as a function of the model parameters $C_{\theta}: \hat{\lambda}=\lambda(\hat{\theta})$. To obtain estimates of the parameters of the dependence structure function, it is necessary to pass from the set of initial samples $\mathbf{X}_{\mathbf{n}}^{(\mathbf{i})}=\left(X_{1}^{(i)}, \ldots, X_{n}^{(i)}\right), 1 \leqslant i \leqslant d$ to samples of uniformly distributed on $[0,1]$ random variables $\mathbf{U}_{\mathbf{n}}^{(\mathbf{i})}=\left(U_{1}^{(i)}, \ldots, U_{n}^{(i)}\right), 1 \leqslant i \leqslant d$. It is necessary to characterize the partial distributions $F_{i}, 1 \leqslant i \leqslant d$. If any of the partial distribution functions is characterized by a set of parameters $\vartheta_{i}, 1 \leqslant i \leqslant d$, the approach is referred to as fully parametric. Otherwise, if the partial distributions are replaced with empirical ones (i.e., the ranging operation is applied) the approach is referred to as semiparametric.

Parametric estimation can be done in one or two stages. In the first case, the parameters of the partial distributions $\vartheta_{i}, 1 \leqslant i \leqslant d$, as well as the parameters $\theta$ of the dependence structure, are estimated together. Typically, the maximum likelihood method is used. In the second case, the assessment takes place in two stages. Due to the very useful property of the copula function, according to which the copula function does not depend on the partial distributions, it is possible to separate the operations of estimating the parameters of the partial distributions $\vartheta_{i}, 1 \leqslant i \leqslant d$ and the parameters of the dependency structure $\theta$. At the first stage, the parameters $\vartheta_{i}$ of the partial distribution functions $F_{i}$ are estimated for $1 \leqslant i \leqslant d$. Then, based on the estimates found, a set of samples is formed

$$
\left(\hat{\mathbf{U}}_{\mathbf{n}}^{(\mathbf{1})}, \ldots, \hat{\mathbf{U}}_{\mathbf{n}}^{(\mathbf{d})}\right)=\left(F_{1, \hat{\vartheta}_{1}}\left(\hat{\mathbf{X}}_{\mathbf{n}}^{(\mathbf{1})}\right), \ldots, F_{d, \hat{\vartheta}_{d}}\left(\hat{\mathbf{X}}_{\mathbf{n}}^{(\mathbf{d})}\right)\right),
$$

using which the parameters $\theta$ of the dependency structure are estimated. This method is also known as the pseudo-maximum likelihood method. 
The semi-parametric approach implies that partial distributions $F_{i}, 1 \leqslant i \leqslant$ $d$ are replaced by empirical distribution functions. Then, as in the previous method, the parameters $\theta$ of the dependency structure are estimated using the maximum likelihood method. As shown in [5], the estimate of the model parameters obtained in this way, as well as the estimate of the tail coefficients, is asymptotically stable and normal. Numerical experiments [4] show that in their properties semi-parametric estimates are almost identical to fully parametric estimates. It should be noted that the use of parametric models of partial distributions $F_{i}, 1 \leqslant i \leqslant d$ can lead to significant errors at the stage of estimating the parameters of the structure of dependence, and, as a consequence, inaccurate and inadequate estimates of the values of the coefficients $\lambda$. The semi-parametric approach is more stable in this sense, since it does not have the described disadvantage.

It is convenient to use functions from the number of two-parameter Archimedean copulas [3] as models of the structures of statistical dependence capable of simulating the tail dependence in the two-dimensional case. Below are the expressions for the copula function and the Archimedean generator of models $\mathrm{BB} 1$ and $\mathrm{BB} 7$

$$
\begin{gathered}
C_{B B 1}(u, v)=\left(1+\left(\left(u^{-\theta}-1\right)^{\delta}+\left(v^{-\theta}-1\right)^{\delta}\right)^{\frac{1}{\delta}}\right)^{-\frac{1}{\theta}}, \\
\delta \geqslant 1, \theta>0, \phi_{B B 1}(w)=\left(w^{-\theta}-1\right)^{\delta} ; \\
C_{B B 7}(u, v)= \\
=1-\left(1-\left(\left(1-(1-u)^{\theta}\right)^{-\delta}+\left(1-(1-u)^{\theta}\right)^{-\delta}-1\right)^{-\frac{1}{\delta}}\right)^{\frac{1}{\theta}}, \\
\delta>0, \quad \theta \geqslant 1, \quad \phi_{B B 7}(w)=\left(1-(1-w)^{\theta}\right)^{-\delta} .
\end{gathered}
$$

These models are convenient in that they allow one to obtain explicit expressions for the tail dependence coefficients. Thus, for model (9)

$$
\lambda_{U}=2-2^{\frac{1}{\delta}}, \quad \lambda_{L}=2^{-\frac{1}{\delta \theta}}, \quad \lambda_{L}=2^{-\frac{1}{\delta}}, \quad \lambda_{U}=2-2^{\frac{1}{\theta}} .
$$

As can be seen from the last formula, the coefficient of the upper tail dependence $\lambda_{U}$ of the model (10) depends only on the model parameter $\theta$ and does not depend on the model parameter $\delta$, whereas the coefficient of the lower tail dependence $\lambda_{L}$ depends only on the parameter $\delta$ and does not depend on $\theta$. This allows parameterization of the model using the coefficients $\lambda_{L}$ and $\lambda_{U}$ :

$$
\delta=-\frac{1}{\log _{2} \lambda_{L}}, \quad \theta=\frac{1}{\log _{2}\left(2-\lambda_{U}\right)},
$$

as well as construction of the modified copula models of Clayton, BB7 and some others [1]. Figure 2 plots the density of the copula BB7 with the corresponding parameters of the tail relationship between the Rosneft and AO Lukoil equities. 

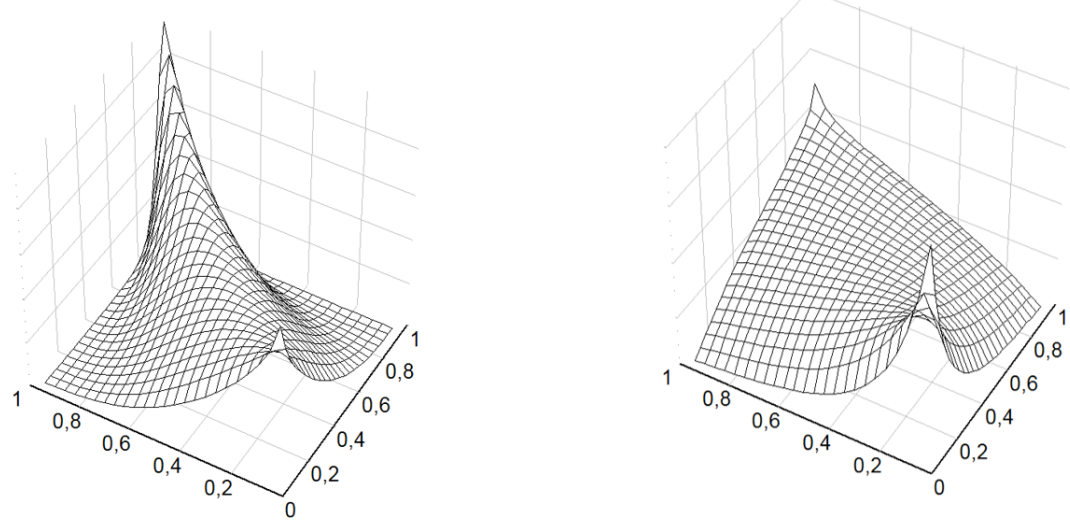

Figure 2. Density of copula BB7, parameterized by the coefficients of the tail dependence. Parameter values: left $\lambda_{L}=0.2, \lambda_{U}=0.8$, right $\lambda_{L}=0.5, \lambda_{U}=0.1$

\section{Parametric approach for elliptic distributions}

The case when the investigated distribution $\left(X^{(1)}, \ldots, X^{(d)}\right)$ is elliptic deserves a separate consideration. Since distributions of elliptic type are symmetric, it is obvious that for $\forall i, j \lambda_{i j, L}=\lambda_{i j, U}$ (below the notation $\lambda_{i j}$ is used). In [5], it was shown that the coefficient $\lambda_{i j}$ of the tail dependence between the components $X^{(i)}$ and $X^{(j)}$ depends only on the index $v$ of regular variation of the elliptic generator, if it is regularly changing, and the value of the parameter $\rho_{i j}$. In this case, the tail dependence coefficient is expressed through these parameters as follows [6]:

$$
\lambda_{i j}=2 \cdot \bar{t}_{v+1}\left(\sqrt{v+1} \sqrt{\frac{1-\rho_{i j}}{1+\rho_{i j}}}\right),
$$

where $\bar{t}_{v+1}$ is the survival function of the Student's distribution with $v+1$ degrees of freedom.

When studying the behavior of the logarithmic increments in the value of shares of the largest issuers of the Russian stock market, we found that the joint distribution of these indicators could be described by the multidimensional Student's distribution, which is known to belong to the class of elliptic distributions [7]. We selected shares of companies Rosneft, Lukoil, Lenta, Mosenergo, Rostelecom; the data were obtained on the website of the Finam company [8]. The results of estimating the parameters of the joint distribution are shown in table 1 . The values correspond to the period from $12 / 15 / 2019$ to 09/30/2020 (ARCH (2) time series model). Table 2 shows the tail dependence matrix calculated from these values, containing pairwise coefficients $\lambda_{i j}$.

The values of $\lambda_{i j}$ in table 2 are significantly greater than zero, which indicates the presence of an extreme type dependence structure. The investigated 
statistical dependence cannot be correctly described by the multivariate normal distribution. In practice, this can lead to a significant underestimation of the risks of extremely high losses when investing in this block of shares.

Table 1

Parameters of joint distribution of logarithmic increments in the value of shares of Russian companies

\begin{tabular}{|c|c|c|c|c|c|}
\hline \multirow{2}{*}{} & \multicolumn{5}{|c|}{ Extreme index $v=4,1$} \\
\cline { 2 - 6 } & Lukoil & Mosenergo & Rostelecom & Lenta & Rosneft \\
\hline Lukoil & 1 & 0,59 & 0,70 & 0,72 & 0,70 \\
\hline Mosenergo & 0,59 & 1 & 0,57 & 0,54 & 0,48 \\
\hline Rostelecom & 0,70 & 0,57 & 1 & 0,67 & 0,60 \\
\hline Lenta & 0,72 & 0,54 & 0,67 & 1 & 0,62 \\
\hline Rosneft & 0,70 & 0,48 & 0,60 & 0,62 & 1 \\
\hline
\end{tabular}

Table 2

Tail dependence matrix of the logarithmic increments distribution of the value of shares of Russian companies

\begin{tabular}{|c|c|c|c|c|c|}
\hline & Lukoil & Mosenergo & Rostelecom & Lenta & Rosneft \\
\hline Lukoil & 1 & 0,30 & 0,39 & 0,40 & 0,39 \\
\hline Mosenergo & 0,30 & 1 & 0,29 & 0,27 & 0,24 \\
\hline Rostelecom & 0,39 & 0,29 & 1 & 0,36 & 0,31 \\
\hline Lenta & 0,40 & 0,27 & 0,36 & 1 & 0,32 \\
\hline Rosneft & 0,39 & 0,24 & 0,31 & 0,32 & 1 \\
\hline
\end{tabular}

\section{Methods for estimating tail dependence indicators using the theory of extreme values}

Let us consider the case when the considered distribution function of random variables $F$ lies in the attraction domain of the distribution of extreme values $G[3]: F \in D A(G)$, i.e.,

$$
\begin{aligned}
\lim _{n \rightarrow \infty} P\left(\frac{\max _{1 \leqslant j \leqslant n} X_{n}-b_{n}}{a_{n}}\right. & \left.\leqslant x, \frac{\max _{1 \leqslant j \leqslant n} Y_{n}-d_{n}}{c_{n}} \leqslant y\right)= \\
& =\lim _{n \rightarrow \infty} F^{n}\left(a_{n} x+b_{n}, c_{n} y+d_{n}\right)=G(x, y)
\end{aligned}
$$


where $a_{n}, c_{n}>0, b_{n}, d_{n} \in \mathbb{R}$. Let us introduce the concept of the limiting indicator of the tail dependence: $\lambda_{U}^{E V}=\lim _{v \rightarrow 1-0} P\left(X>G_{1}^{-1}(v) \mid Y>G_{2}^{-1}(v)\right)$, where $G_{1}, G_{2}$ - partial distribution functions of the extreme joint distribution function $G$. Then the following theorem is true:

Theorem 1. For a distribution function lying in the attraction domain of the distribution function of extreme values $G$, the tail dependence index $\lambda_{U}$ coincides with the extreme tail dependence index $\lambda_{U}^{E V}$. tion

Proof. We use the transformation proposed in [9], passing to the distribu-

$$
F_{*}(x, y)=F\left(\left(\frac{1}{1-F_{1}}\right)^{-1}(x),\left(\frac{1}{1-F_{2}}\right)^{-1}(y)\right),
$$

that lies in the attraction domain of the distribution

$$
G_{*}(x, y)=G\left(\left(\frac{1}{-\ln G_{1}}\right)^{-1}(x),\left(\frac{1}{-\ln G_{2}}\right)^{-1}(y)\right) \text {. }
$$

The partial distributions $G_{* 1}, G_{* 2}$ have the form of Frechet distribution functions with the parameter $\gamma=1$ (standard Frechet distribution):

$$
G_{* 1}=G_{* 2}=\Phi_{1}(x) \begin{cases}e^{-\frac{1}{x}}, & x>0, \\ 0, & x \leqslant 0 .\end{cases}
$$

Limit relation (??) for functions $F_{*}$ and $G_{*}$ takes the form

$$
\lim _{n \rightarrow \infty} F_{*}^{n}(n x, n y)=G_{*}(x, y) \text {, }
$$

or, similarly

$$
\lim _{n \rightarrow \infty} n\left(1-F_{*}(n x, n y)\right)=-\ln G_{*}(x, y) .
$$

Omitting the intermediate derivations, we obtain from equation (13)

$$
\begin{array}{r}
-\ln G_{*}(t, t)=\lim _{n \rightarrow \infty} n\left(1-F\left(\left(\frac{1}{1-F_{1}}\right)^{-1}(n t),\left(\frac{1}{1-F_{2}}\right)^{-1}(n t)\right)\right)= \\
=\lim _{n \rightarrow \infty} n\left(\frac{1}{n t}+\frac{1}{n t}-\lambda_{U} \frac{1}{n t}\right)=\frac{2-\lambda_{U}}{t} .
\end{array}
$$

By definition (12), the distribution of extreme values $G_{*}$ is obtained from the original distribution $G$ using a monotonic transformation. This means that the copula functions of these distributions coincide. Using this fact and the result obtained above for $\ln G_{*}(t, t)$, we have:

$$
\lambda_{U}^{E V}=\lim _{v \rightarrow 1-0} \frac{1-2 v+C_{E V}(v, v)}{1-v}=\lim _{v \rightarrow 1-0} \frac{1-2 v+G_{*}\left(-\frac{1}{\ln v},-\frac{1}{\ln v}\right)}{1-v}=
$$




$$
=\lim _{v \rightarrow 1-0} \frac{1-2 v+e^{\ln v\left(2-\lambda_{U}\right)}}{1-v}=\lim _{v \rightarrow 1-0} \frac{1-2 v+v^{2-\lambda_{U}}}{1-v}=\lambda_{U}
$$

A similar result is, of course, also valid for the lower tail coefficient and the limiting distribution of block minima. This property allows, when estimating the tail coefficient, to go from the entire available sample to its extreme values (block extrema). At the same time, a distinction is made between semi- and fully parametric approaches to estimating the parameters of the resulting distribution. In the case of using a semi-parametric approach, the parameters of the limiting structure of dependence [3] are estimated from

$$
\left(\hat{U}_{\max i}, \hat{V}_{\max i}\right)=\left(\operatorname{Rank}\left(\hat{X}_{\max i}\right), \operatorname{Rank}\left(\hat{Y}_{\max i}\right)\right), \quad 1 \leqslant i \leqslant\left\lfloor\frac{n}{k}\right\rfloor,
$$

where $\hat{X}_{\max i}=\bigvee_{j=1}^{k} X_{(i-1) k+j}, \hat{Y}_{\max i}=\bigvee_{j=1}^{k} Y_{(i-1) k+j}, 1 \leqslant k<n, 1 \leqslant i \leqslant\left\lfloor\frac{n}{k}\right\rfloor$. As a model of the structure of the dependence of the limiting distribution of extrema, we have proposed various functions of copula of the extreme type, in particular, the Gumbel model (logistic model):

$$
C_{E V}(u, v)=\exp \left(-\left((-\ln u)^{R}+(-\ln v)^{R}\right)^{\frac{1}{R}}\right), \quad R \geqslant 1 .
$$

The estimate of the coefficient of the upper tail dependence for model (14) has the form $\lambda_{U}^{E V}(k)=2-2^{\frac{1}{R_{U^{(k)}}}}$. The formulas for estimating the coefficient of the lower tail dependence are completely similar. They were obtained by passing to the distribution of the maxima of the quantities $(-X,-Y)$ :

$$
\begin{gathered}
\hat{X}_{\min i}=\max _{1 \leqslant j \leqslant n}\left(-X_{(i-1) k+j}\right), \quad \hat{Y}_{\min i}=\max _{1 \leqslant j \leqslant n}\left(-Y_{(i-1) k+j}\right), \\
1 \leqslant k<n, \quad 1 \leqslant i \leqslant\left\lfloor\frac{n}{k}\right\rfloor, \\
\left(\hat{U}_{\min i}, \hat{V}_{\min i}\right)=\left(\operatorname{Rank}\left(\hat{X}_{\min i}\right), \operatorname{Rank}\left(\hat{y}_{\min i}\right)\right), \quad 1 \leqslant i \leqslant\left\lfloor\frac{n}{k}\right\rfloor, \\
\lambda_{L}(k)=2-2^{\frac{1}{R_{L}(k)} .}
\end{gathered}
$$

An alternative approach to characterizing the distribution function of extreme values is the peaks over threshold (POT) method. A detailed description of this approach can be found in [10]. We only note that the idea of the method is to characterize the limiting distribution of excesses that have exceeded a given threshold value. In [4], it was proposed to evaluate the value of the upper tail coefficient by considering the values of the points of the investigated structure of the dependence $(U, V)$ lying in the region $[t, 1]^{2}$, where $t$ is the threshold parameter tending to 1 :

$$
\left(\hat{\mathbf{U}}_{\mathbf{U}}^{*}, \hat{\mathbf{V}}_{\mathbf{U}}^{*}\right)=\left\{\left(U_{j}, V_{j}\right):\left(U_{j}, V_{j}\right) \in[t, 1] \times[t, 1]\right\}, \quad 0 \leqslant t<1 .
$$


To estimate the lower tail coefficient, values from the region $[0, t]^{2}, t \rightarrow 0$ should be considered:

$$
\left(\hat{\mathbf{U}}_{\mathbf{L}}^{*}, \hat{\mathbf{V}}_{\mathbf{L}}^{*}\right)=\left\{\left(U_{j}, V_{j}\right):\left(U_{j}, V_{j}\right) \in[0, t] \times[0, t]\right\}, \quad 0<t \leqslant 1 .
$$

In [9], a relation was proved that makes it possible to estimate the parameter $\lambda_{L}$ in the case when the quantities $(X, Y)$ under consideration are related by the Archimedean structure of the dependence. The authors showed that if a copula $C$ has an Archimedean generator with an index of regular variation $\alpha>0$, then the lower threshold copula

$$
C_{L, t}(u, v)=P(U \leqslant u, V \leqslant v \mid U \leqslant t, V \leqslant t),
$$

converges in the limit at $t \rightarrow 0$ to the Clayton copula $C_{\alpha}$ with parameter $\delta=\alpha$ :

$$
\lim _{t \rightarrow 0} C_{L, t}(u, v)=C_{C l}(u, v), \quad \forall u, v \in[0,1],
$$

where $C_{C l}(u, v)=\left(u^{-\delta}+v^{-\delta}-1\right)^{-\frac{1}{\delta}}$ is an Archimedean copula with generator $\phi(w)=w^{-\delta}-1, \delta>0$. This dependence structure model has a lower tail dependence with coefficient $\lambda_{L}=2^{-\frac{1}{\delta}}$.

In the case when the type of the investigated structure of dependence $(U, V)$ is not Archimedean, one should choose another model of the limiting copula capable of simulating the tail dependence. For example, it is convenient to use the Gumbel model in the form (14) to model the upper threshold copula

$$
C_{U, t}(u, v)=P(U>u, V>v \mid U>t, V>t), \quad 0 \leqslant t<1,
$$

and the inverse Gumbel copula $\bar{C}_{E V}(u, v)=C_{E V}(1-u, 1-v)+u+v-1$ for modeling the lower threshold copula (15).

The disadvantage of the threshold method is that when the threshold parameter $t$ is close to 0 (when estimating the coefficient of the lower tail dependence) and 1 (when estimating the coefficient of the upper tail dependence), too few points fall into the region where the threshold is exceeded, which makes it impossible to estimate tail parameters with sufficient accuracy. If the threshold is too low, the extreme copula (14) ceases to be an adequate model of the truncated structure of the dependence, which leads to significant systematic errors. The so-called bias-variance problem arises. To solve it, it was proposed to use a combined threshold approach [3]. The essence of the method is that the threshold model of the structure of dependence could adequately describe both the behavior of the entire sample and its points lying in the region of extreme values for different values of the parameters. Then, even at low values of the threshold $t$, one can count on the stability of the estimates obtained. We propose to use models (9), (10) as such flexible structures of dependence. These models are very versatile and make it possible to simulate both the integral structure of dependence and its behavior in extreme areas.

To test the described models of tail dependence, we used samples $\mathbf{X}_{n}$, $\mathbf{Y}_{\mathbf{n}}$ from a two-dimensional distribution with the structure of a mixed-type dependence 


$$
C_{m i x}(u, v)=\frac{1}{2} C_{C l_{1}}(u, v)+\frac{1}{2} \bar{C}_{C l_{2}}(u, v),
$$

where $C_{C l_{1}}$ is the Clayton copula with parameter $\delta_{1}=3.11, \bar{C}_{C l_{2}}$ is the inverse Clayton copula with the parameter $\delta_{2}=1.36$. The coefficients of the lower and upper tail dependences of copula (17) are, respectively, equal to

$$
\begin{aligned}
& \lambda_{L}^{*}=\frac{1}{2} \lambda_{L, 1}+\frac{1}{2} \lambda_{L, 2}=\frac{1}{2} \cdot 2^{-\frac{1}{\delta_{1}}}+\frac{1}{2} \cdot 0=0.40, \\
& \lambda_{U}^{*}=\frac{1}{2} \lambda_{U, 1}+\frac{1}{2} \lambda_{U, 2}=\frac{1}{2} \cdot 0+\frac{1}{2} \cdot 2^{-\frac{1}{\delta_{2}}}=0.30 .
\end{aligned}
$$

Figures 3,4 show the plots of the estimates obtained by the block extremum method and the threshold method. As can be seen, the combined threshold method provides greater stability of estimates depending on the parameter $t$.
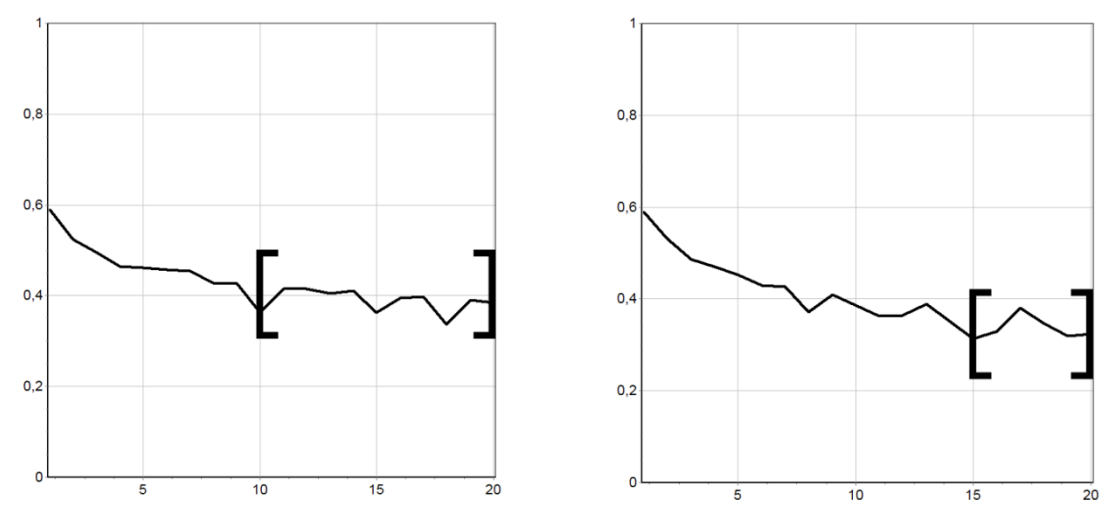

Figure 3. Estimation of indicators of tail distribution coefficients of block minima (left) and block maxima (right) depending on the parameter $k$
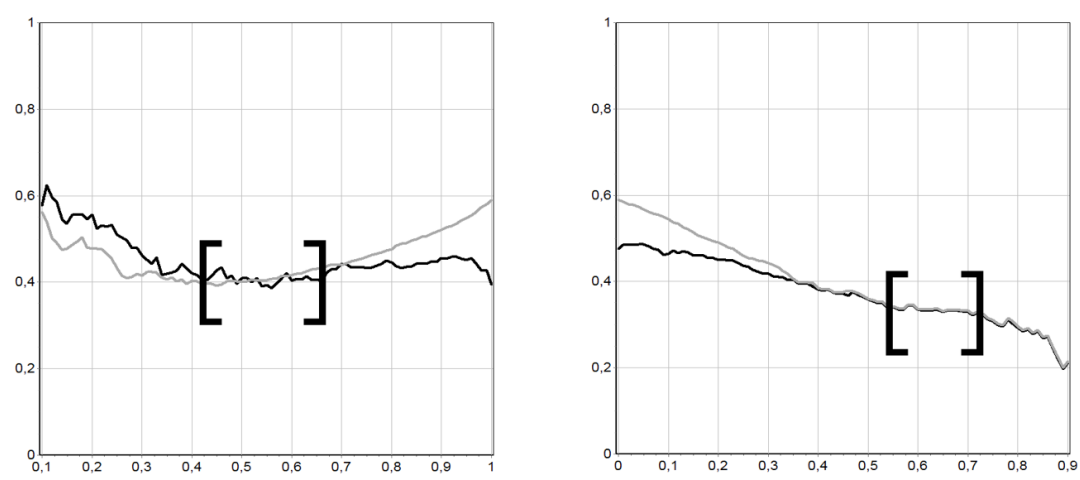

Figure 4. Estimation of indicators of the lower (left) and upper (right) tail distribution coefficients depending on the threshold parameter $t$. model BB1, model Gumbel 


\section{Conclusion}

This paper proposes and investigates methods for analyzing the financial performance of companies in the context of increased volatility in stock markets associated with the global COVID-19 pandemic, as well as a decline in oil prices during the period 12/15/2019 - 09/30/2020. Computer experiments are carried out to assess the riskiness of investments in leading Russian companies and to analyze the value of shares of leading Russian companies, and the advantages of their application are shown in comparison with the classical multivariate analysis using a Gaussian distribution. Analysis of the properties of estimates of the tail dependence coefficients showed their high sensitivity to extreme changes in the value of companies' shares, which makes it possible to use them as indicators of the occurrence of extreme events in the stock markets and to make timely decisions on the management of their investment projects.

\section{References}

[1] E. Y. Shchetinin, "On new approaches to company management in emergency situations [Novyh podhodah $\mathrm{k}$ upravleniyu kompaniej v chrezvychajnyh situaciyah]," Finansy i kredit, vol. 30, no. 198, pp. 7175, 2005, In Russian.

[2] E. Y. Shchetinin, K. M. Nazarenko, and A. V. Paramonov, "Instrumental methods of stochastic analysis of extreme events [Instrumental'nye metody stohasticheskogo analiza ekstremal'nyh sobytij]," Vestnik NNGU, Matematicheskoye modelirovaniye $i$ optimal'noye upravleniye, vol. 2, no. 29, pp. 56-63, 2004, In Russian.

[3] V. A. Akimov, A. A. Bykov, and E. Y. Shchetinin, Introduction to statistics of extreme values, EMERCOM of Russia /Vvedenie v statistiku ekstremal'nyh znachenij $i$ ee prilozheniya/. Moscow: FGU VNII GOChS (FTs), 2009, 524 pp., In Russian.

[4] R. Schmidt and U. Stadtmüller, "Non-parametric estimation of tail dependence," Scandinavian Journal of Statistics, vol. 33, no. 2, pp. 307$335,2006$.

[5] R. Schmidt, Tail dependence. In Statistical tools in finance and insurance, W. Hardle, P. Cizek, and R. Weron, Eds. Springer Verlag, 2003.

[6] G. Frahm, M. Junker, and A. Szimayer, "Elliptical copulas: Applicability and limitations," Statistics \&6 Probability Letters, vol. 63, no. 3, pp. 275286, 2003. DOI: $10.1016 / \mathrm{S} 0167-7152$ (03) 00092-0.

[7] S. Resnick, Extreme values, regular variation and point processes. Berlin: Springer, 1987.

[8] E. Y. Shchetinin, "Vine copulas structures modeling on Russian stock market," Discrete and Continuous Models and Applied Computational Science, vol. 27, no. 4, pp. 343-354, 2019. DOI: 10.22363/2658-46702019-27-4-343-354. 
[9] E. Y. Shchetinin, "Modeling of D-branching structures in the Russian stock market [Modelirovanie struktur D-vetvlenij na rossijskom fondovom rynke]," Vestnik komp'yuternykh $i$ informatsionnykh tekhnologiy, vol. 8, no. 182, pp. 38-45, 2019, In Russian.

[10] C. Genest, K. Ghoudi, and L. Rivest, "A semiparametric estimation procedure of dependence parameters in multivariate families of distributions," Biometrika, vol. 82, no. 3, pp. 543-552, 1995. DOI: 10.1093/ biomet/82.3.543.

\section{For citation:}

E. Yu. Shchetinin, On methods of quantitative analysis of the company's financial indicators under conditions of high risk of investments, Discrete and Continuous Models and Applied Computational Science 28 (4) (2020) 346-360. DOI: $10.22363 / 2658-4670-2020-28-4-346-360$.

\section{Information about the authors:}

Shchetinin, Eugeny Yu. - Doctor of Physical and Mathematical Sciences, lecturer of Department of Data Analysis, Decision Making and Financial Technologies (e-mail: riviera-molto@mail.ru, phone: +7(917)5390698, ORCID: https://orcid.org/0000-0003-3651-7629, ResearcherID: O-8287-2017, Scopus Author ID: 16408533100) 
УДК 519.7:338.67

DOI: $10.22363 / 2658-4670-2020-28-4-346-360$

\title{
О методах количественного анализа финансовых показателей компании в условиях высокой рискованности инвестиций
}

\author{
Е. Ю. Щетинин
}

Финансовый университет при Правительстве Российской Федерации Ленинградский проспект, д. 49, Москва, 125993, Россия

В работе исследованы методы количественного анализа скрытых статистических связей финансовых показателей компаний в условиях высокой рискованности инвестирования. Предложен новый полупараметрический метод оценивания показателей хвостовой зависимости с использованием моделей структур зависимости BB1 и BВ7. Для набора данных, содержащих стоимостные показатели ведущих российских компаний, проведены компьютерные эксперименты, в результате которых показано, что предложенный метод обладает более высокой устойчивостью и точностью по сравнению с другими рассмотренными методами. Практическое применение представленного метода управления рисками позволило бы финансовым компаниям адекватно оценивать инвестиционные риски в условиях наступления экстремальных событий.

Ключевые слова: финансовые показатели, глубокие статистические связи, структуры зависимости, хвостовой коэффициент, копула 